\title{
Effect of machining parameters on surface finish of Inconel 718 in end milling
}

\author{
Bapi Sarkar, Moola Mohan Reddy and Sujan Debnath \\ Faculty of Engineering and Science Curtin University, CDT 250 Miri, Sarawak 98009, Malaysia
}

\begin{abstract}
Surface finish is an important criteria in machining process and selection of proper machining parameters is important to obtain good surface finish. In the present work effects of the machining parameters in end milling of Inconel 718 were investigated. Central composite design was used to design the total number of experiments. A Mathematical model for surface roughness has been developed using response surface methodology. In this study, the influence of cutting parameters such as cutting speed, feed rate and depth of cut on surface roughness was analyzed. The study includes individual effect of cutting parameters on surface roughness as well as their interaction. The analysis of variance (ANOVA) was employed to find the validity of the developed model. The results show that depth of cut mostly affected the surface roughness. It is also observed that surface roughness values are comparable in both dry and wet machining conditions.
\end{abstract}

\section{Introduction}

Inconel 718 is a well known nickel-based super alloy used in structural materials because of its high strengthto-weight ratio, fracture toughness, fatigue strength, corrosion resistance and ability to operate at high temperatures. Nickel alloys are broadly used in petrochemical, automotive, aerospace, marine, nuclear sectors and biomedical $[1,2]$. Although these materials are widely preferred, their machinability is not at the desired level. The reason for this is due to their thermal and mechanical properties, which limit the machinability of Nickel based alloys during the machining process [3, 4]. Surface roughness is significantly influenced by cutting speed, feed rate and depth of cut. Therefore, it is necessary to develop predictive mathematical models in order to determine the surface roughness, in advance (before the actual machining is performed). There are a large number of tools available to develop predictive models for machining processes, namely Response Surface Methodology (RSM), Artificial Neural Network (ANN), Taguchi method, etc [5-9]. Among all predictive model technique, RSM is a widely used tool for designing experiments and analyzing data to predict model and to select the best mathematical model that represents the real life experimental results [10]. ANN model produced more percentage error as compare to RSM model in turning of $\mathrm{Al} 7050 / 10 / \mathrm{SiCp}$ and $\mathrm{Al} 7075$ composites [11]. Choudhary and Baradie [12] developed response model for tool life surface roughness and cutting force with central composite method using RSM. They found it very useful for assessing the maximum tool life and surface finish. A good design of the experiment and an accurate predictive model need to be developed to minimize the number of experiments optimizing the cutting parameters for desired machinability.

The cutting parameters are an important criterion to obtain good machinability of Nickel-based super alloys [13-15]. Liaoa et al. [16] experimented end milling of Inconel 718 under various cutting speeds by cemented carbide tools for slot and side milling. The results show that cutting speed in the range of 90 to $110 \mathrm{~m} / \mathrm{min}$ is appropriate for slot milling, and 55 to $135 \mathrm{~m} / \mathrm{min}$ is appropriate for side milling. Devillez et al. [17] Performed wet and dry turning tests at various cutting speeds using TiCN/Al2O3 coated carbide tool inserts. The results show an acceptable surface quality for a cutting speed of $60 \mathrm{~m} / \mathrm{min}$ in the dry condition. At the same cutting speed, the result also shows the same order of residual stress and micro hardness for both dry and wet conditions. Zhaopeng et al. [18] studied tool wear pattern in the dry machining of Inconel 718 with PVD coated cemented carbide tool. Their study shows that build up edge (BUE) was formed at a low cutting speed of 20 $\mathrm{m} / \mathrm{min}$ which resulted in chipping and tool wear. While at a high cutting speed range of $45 \mathrm{~m} / \mathrm{min}$ to $50 \mathrm{~m} / \mathrm{min}$, the wear debris diffused between the tool and the work piece, which accelerated the BUE and peeling wear debris.

Coolants and its influence on machinability have been discussed thoroughly in available literature $[19,20]$. Yazid et al. [21] investigated the effect of cutting parameters and machining conditions on surface integrity for turning Inconel 718. They reported that at low speed of $90 \mathrm{~m} / \mathrm{min}$ and $120 \mathrm{~m} / \mathrm{min}, 50 \mathrm{ml} / \mathrm{h}$ of lubricant shows a better surface roughness compared to $100 \mathrm{ml} / \mathrm{h}$ lubricant and the dry condition. Kamata and Obikawa [22] applied 
MQL while using three different coated carbide tools TiCN/Al2O3/TiN (CVD), TiN/AlN superlattice (PVD) and TiAIN (PVD) for Inconel 718 in turning and reported that air pressure is an important parameter influencing tool life and surface finish. Zhang et al. [23] investigated the effects of different cutting conditions on the tool life and cutting forces in end milling Inconel 718 with a combination of TiAlN and TiN coated tools. They reported a combination of cryogenic compressed air and the microdroplets of biodegradable vegetable oil significantly reduced the tool wear compared to the dry cutting condition. Pusaveca et al. [24] examined the effects of cutting fluid on surface integrity in turning of Inconel 718. The result shows that the combination of cryogenic machining and cutting fluid provides a better surface finish compared to cutting fluid alone.

\section{Experimental designs}

In all conventional machining process, the most influential machining parameters are cutting speed, feed rate and depth of cut. A proper combination of machining parameters is very important to achieve good machinability. The design of experiments is done by using Central Composite Design (CCD) technique to minimize the number of experiments For CCD, the number of experiments required can be determined from Eq. 1.

$$
n=2^{k}+2 k+c
$$

Where $\mathrm{n}$ represents the number of experimentations, $\mathrm{k}$ is the total number of parameters considered.

The experimental results are used to develop predictive models by using response surface method for surface roughness. The proposed relationship between the output response and input variables can be represented by Eq. 2

$$
\begin{aligned}
& R=b_{0}+b_{1} \times A+b_{2} \times B+b_{3} \times C+b_{11} \times A^{2}+b_{22} \times B^{2}+b_{33} \\
& \times C^{2} \times b_{12} \times A B+b_{23} \times B C+b_{13} \times A C
\end{aligned}
$$

Where $\mathrm{R}$ is the response and $\mathrm{A}, \mathrm{B}$, and $\mathrm{C}$ are the different machining factors. The regression coefficients $b i=1,2,3$ is computed by the regression method using experimental results. The significance of factors and their interactions is computed using statistical analysis. Optimum response model and setting of parameters are produced by using the response model in Eq. 2. A total 20 run or set of experiments were conducted with different cutting parameters on basis of CCD and the surface finish is recorded for each run. Table 1 shows the range of cutting parameters used in the experiments. The adequacy of the quadratic model evaluated using the analysis of variance
(ANOVA). Design expert 9.0 was used to establish the design matrix and to analyze the experimental data.

Table 1. Machining parameters.

\begin{tabular}{|c|c|c|c|}
\hline $\begin{array}{c}\text { Cutting } \\
\text { parameters }\end{array}$ & Notation & Unit & Range \\
\hline Cutting speed & $V_{c}$ & $\mathrm{rpm}$ & 1200 to 2500 \\
\hline Feed rate & $f$ & $\mathrm{~mm} / \mathrm{rev}$ & 0.1 to 0.5 \\
\hline Depth of cut & $D_{c}$ & $\mathrm{~mm}$ & 0.1 to 0.5 \\
\hline
\end{tabular}

\section{Experimental setup}

The work piece material used is Inconel 718. Rectangle block of $202 \mathrm{~mm} \times 102 \mathrm{~mm} \times 12 \mathrm{~mm}$. The general properties are listed on the table for Inconel 718. The experiments are conducted on V30 Horizontal CNC machine (Lead well). The cutting tool was a six flute Mitsubishi milling tool (VC- 8MH). The first test was carried out in dry condition followed by wet condition with a similar experimental setup. According to the experimental setup and cutting parameters the cutting length was $112 \mathrm{~mm}$ the average interval of one cutting pass is about 0.75 min. After each cutting pass, the surface roughness was checked, and the tool removed to observe tool wear under optical microscope after the observation the tool is again fixed to the tool holder for next set of experiments. Similarly, after each cutting pass the surface roughness was measured by surface roughness tester (Mitutoyo SJ-210), the procedure was repeated until the tool failed for both dry and wet conditions.

\section{Experimental result and discussion}

To predict the surface roughness in end milling of Inconel 718, the surface roughness value of each run was input and RSM was performed. Table 2 and Table 3 shows the CCD matrix, with variable cutting parameters and experimental surface roughness for a dry condition and wet conditions.

Based on the experimental results second order predictive models have been developed for surface roughness by using Response Surface Method. The obtained equations for the response factors are given below in equation 3 . The Fit and summary test suggested that model is significant for dry condition.

$$
\begin{array}{r}
R a=0.33303-4.37501 \times 10^{-5} \times A+3.06384 \times 10^{-3} \times B- \\
0.11178 \times C \times 3.07692 \times 10^{-7} \times A B-5.70923 \times 10^{-} \\
{ }^{5} \times A C+2.0 \times 10^{-3} \times B C+1.17619 \times 10^{-7} \times A^{2} \times-1.38276 \times 10^{-5} \\
\times B^{2}+0.40266 \times C^{2}
\end{array}
$$

\begin{tabular}{|c|c|c|c|c|c|c|}
\hline \multirow[t]{2}{*}{ Exp. no } & \multirow{2}{*}{$\begin{array}{c}\text { Run } \\
\text { order }\end{array}$} & \multirow{2}{*}{$\begin{array}{l}\text { Cutting speed } \\
\left(V_{\partial}\right) \mathrm{rpm}\end{array}$} & \multirow{2}{*}{$\begin{array}{c}\text { Feed rate }(f) \\
\mathrm{mm} / \mathrm{rev}\end{array}$} & \multirow{2}{*}{$\begin{array}{l}\text { Depth of cut } \\
\left(D_{c}\right) \mathrm{mm}\end{array}$} & \multicolumn{2}{|c|}{ Surface roughness (Ra) $\mu \mathrm{m}$} \\
\hline & & & & & Dry Condition & Wet condition \\
\hline 1 & 5 & 1200 & 100 & 0.5 & 0.31 & 0.29 \\
\hline
\end{tabular}

Table 2. Cutting parameter of experiments and resultant surface roughness. 


\begin{tabular}{|c|c|c|c|c|c|c|}
\hline 2 & 7 & 1200 & 150 & 0.5 & 0.33 & 0.31 \\
\hline 3 & 6 & 2500 & 100 & 0.5 & 0.30 & 0.27 \\
\hline 4 & 20 & 1850 & 125 & 0.3 & 0.19 & 0.19 \\
\hline 5 & 8 & 2500 & 150 & 0.5 & 0.36 & 0.3 \\
\hline 6 & 15 & 1850 & 125 & 0.3 & 0.28 & 0.23 \\
\hline 7 & 18 & 2500 & 150 & 0.3 & 0.22 & 0.22 \\
\hline 8 & 4 & 1850 & 125 & 0.1 & 0.23 & 0.18 \\
\hline 9 & 13 & 1850 & 150 & 0.1 & 0.17 & 0.20 \\
\hline 10 & 17 & 1850 & 125 & 0.3 & 0.10 & 0.11 \\
\hline 11 & 14 & 1850 & 125 & 0.5 & 0.34 & 0.30 \\
\hline 12 & 19 & 1850 & 125 & 0.3 & 0.30 & 0.27 \\
\hline 13 & 16 & 1850 & 125 & 0.3 & 0.17 & 0.18 \\
\hline 14 & 2 & 2500 & 125 & 0.1 & 0.23 & 0.19 \\
\hline 15 & 3 & 1200 & 100 & 0.1 & 0.19 & 0.15 \\
\hline 16 & 12 & 1850 & 167 & 0.3 & 0.24 & 0.20 \\
\hline 17 & 10 & 2943 & 125 & 0.3 & 0.37 & 0.33 \\
\hline 18 & 11 & 1850 & 83 & 0.3 & 0.13 & 0.19 \\
\hline 19 & 1 & 1200 & 100 & 0.1 & 0.19 & 0.13 \\
\hline 20 & 9 & 757 & 125 & 0.3 & 0.33 & 0.27 \\
\hline
\end{tabular}

Similarly, the obtained equations for the response factors are given below in equation 4 . The Fit and summary test suggested that model is significant for wet condition.

$$
\begin{array}{r}
R a=0.020757-2.78250 \times 10^{-4} \times A+6.00110 \times 10^{-3} \times B- \\
0.23374 \times C \times 1.53846 \times 10^{-7} \times A B-.84615 \times 10^{-} \\
{ }^{3} \times A C+2.50000 \times 10^{-3} \times B C+7.9276 \times 10^{-8} \times A^{2} \times- \\
2.56293 \times 10^{-5} \times B^{2}+0.39504 \times C^{2}
\end{array}
$$

The developed model is verified by using ANOVA and results are shown in Table 3 and 4 . From the table, The Model F-value of 3.70 implies the model is significant, and the Values of "Prob $>$ F" less than 0.0500 indicate model terms are significant. From the ANOVA result, it is clear that the value of factor $\mathrm{A}, \mathrm{B}, \mathrm{C}$ have effects on surface roughness. The depth of cut influenced more significantly influence on surface roughness compare to cutting speed and feed rate.

\begin{tabular}{|c|c|c|c|c|c|c|}
\hline Source & Sum of Squares & df & Mean Square & F Value & $\begin{array}{c}\text { p-value } \\
\text { Prob }>\text { F }\end{array}$ & \\
\hline Model & 0.065 & 9 & 7.232E-003 & 3.70 & 0.0267 & significant \\
\hline A-Speed & $2.956 E-003$ & 1 & $2.956 E-003$ & 1.51 & 0.2468 & \\
\hline B-Feed rate & $3.370 E-003$ & 1 & $3.370 E-003$ & 1.73 & 0.2183 & \\
\hline C-Depth of cut & 0.033 & 1 & 0.033 & 16.73 & 0.0022 & \\
\hline$A B$ & $5.000 E-005$ & 1 & $5.000 E-005$ & 0.026 & 0.8761 & \\
\hline
\end{tabular}

Table 3. ANOVA table for surface roughness for dry condition.

\begin{tabular}{|c|c|c|c|c|c|c|}
\hline Source & $\begin{array}{c}\text { Sum of } \\
\text { Squares }\end{array}$ & df & $\begin{array}{c}\text { Mean } \\
\text { Square }\end{array}$ & $\begin{array}{c}\text { F } \\
\text { Value }\end{array}$ & $\begin{array}{c}\text { p-value } \\
\text { Prob }>\text { F }\end{array}$ & significant \\
\hline Model & 0.090 & 9 & $9.990 \mathrm{E}-003$ & 3.41 & 0.0346 & \\
\hline A-Speed & $2.049 E-003$ & 1 & $2.049 E-003$ & 0.70 & 0.4224 & \\
\hline$B$-Feed rate & $5.142 E-003$ & 1 & $5.142 E-003$ & 1.76 & 0.2145 & \\
\hline -Depth of cut & 0.041 & 1 & 0.041 & 13.92 & 0.0039 & \\
\hline$A B$ & $2.000 E-004$ & 1 & $2.000 E-004$ & 0.068 & 0.7991 & \\
\hline$A C$ & $4.500 E-004$ & 1 & $4.500 E-004$ & 0.15 & 0.7032 & \\
\hline$B C$ & $8.000 E-004$ & 1 & $8.000 E-004$ & 0.27 & 0.6125 & \\
\hline$A^{\wedge} 2$ & 0.036 & 1 & 0.036 & 12.16 & 0.0059 & \\
\hline$B^{\wedge} 2$ & $1.076 E-003$ & 1 & $1.076 E-003$ & 0.37 & 0.5578 & \\
\hline$C^{\wedge} 2$ & $3.739 E-003$ & 1 & $3.739 E-003$ & 1.28 & 0.2848 & not significant \\
\hline Residual & 0.029 & 10 & $2.927 \mathrm{E}-003$ & & & 0.9933 \\
\hline Lack of Fit & $2.072 E-003$ & 5 & $4.145 E-004$ & 0.076 & & \\
\hline Pure Error & 0.027 & 5 & $5.440 E-003$ & & & \\
\hline Cor Total & 0.12 & 19 & & & & \\
\hline
\end{tabular}

Table 4. ANOVA table for surface roughness for dry condition. 


\begin{tabular}{|c|c|c|c|c|c|c|}
\hline$A C$ & $2.000 E-004$ & 1 & $2.000 E-004$ & 0.10 & 0.7556 & \\
\hline$B C$ & $1.250 E-003$ & 1 & $1.250 E-003$ & 0.64 & 0.4423 & \\
\hline$A^{\wedge} 2$ & 0.016 & 1 & 0.016 & 8.27 & 0.0165 & \\
\hline$B^{\wedge} 2$ & $3.698 E-003$ & 1 & $3.698 E-003$ & 1.89 & 0.1989 & \\
\hline$C^{\wedge} 2$ & $3.598 E-003$ & 1 & $3.598 E-003$ & 1.84 & 0.2046 & \\
\hline Residual & 0.020 & 10 & $1.953 E-003$ & & & \\
\hline Lack of Fit & $4.735 E-003$ & 5 & $9.470 E-004$ & 0.32 & 0.8817 & not significant \\
\hline Pure Error & 0.015 & 5 & $2.960 E-003$ & & & \\
\hline Cor Total & 0.085 & 19 & & & & \\
\hline
\end{tabular}

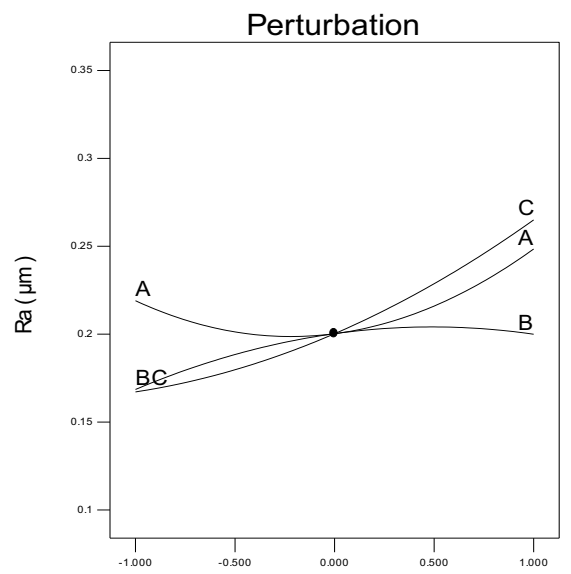

Deviation from Reference Point (Coded Units) Figure 1. Perturbation plot Ra Vs A, B, C.

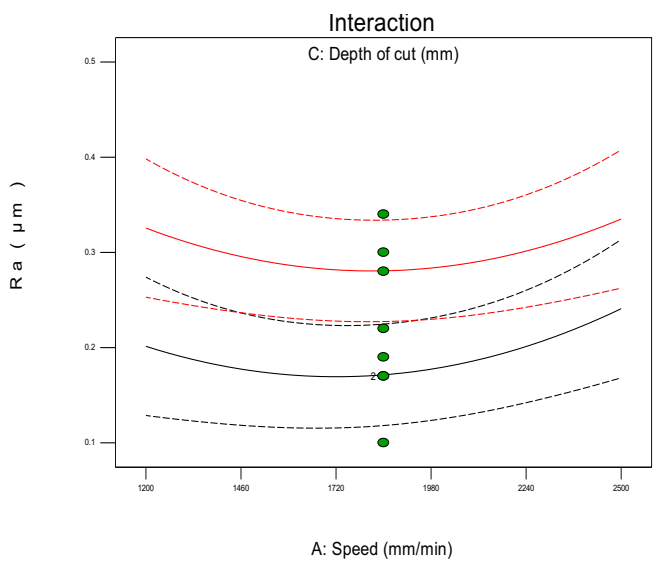

Figure 3. Interaction plot $\mathrm{A}$ and $\mathrm{C}$.

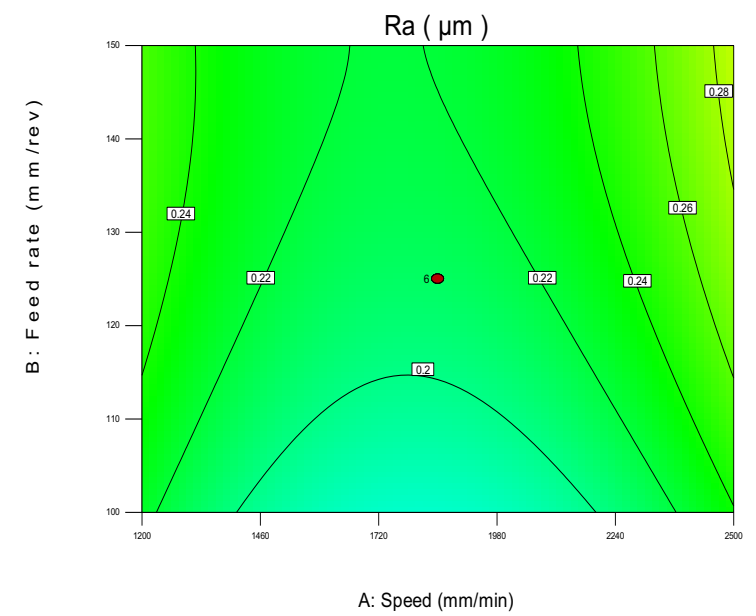

Figure 5. Ra contour plot Vs A, B.

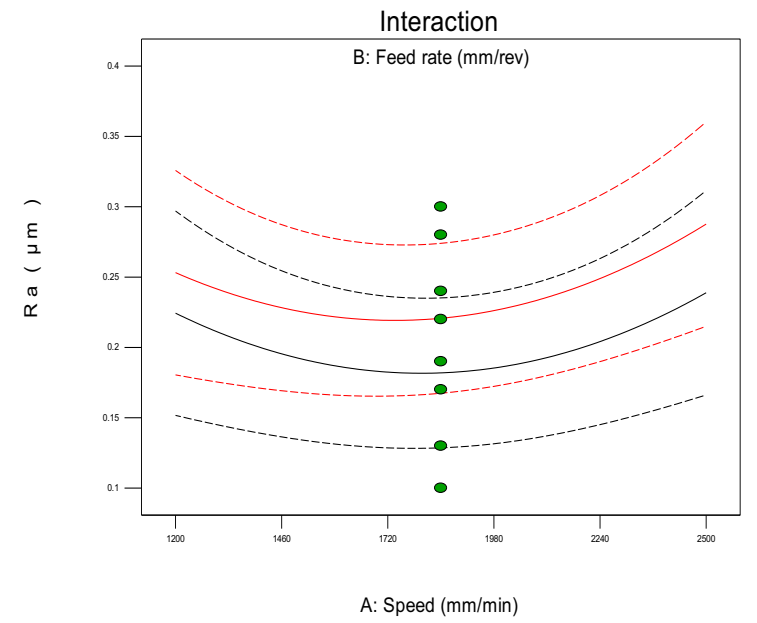

Figure 2. Interaction plot A and B.

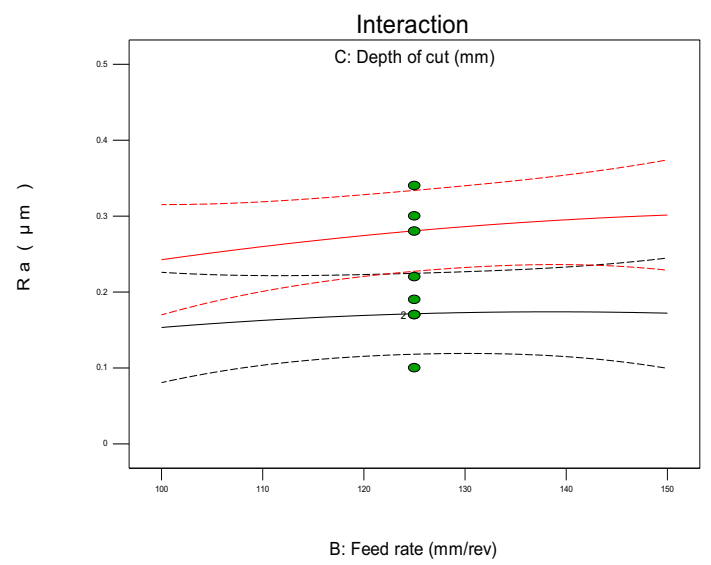

Figure 4. Interaction plot B and C.

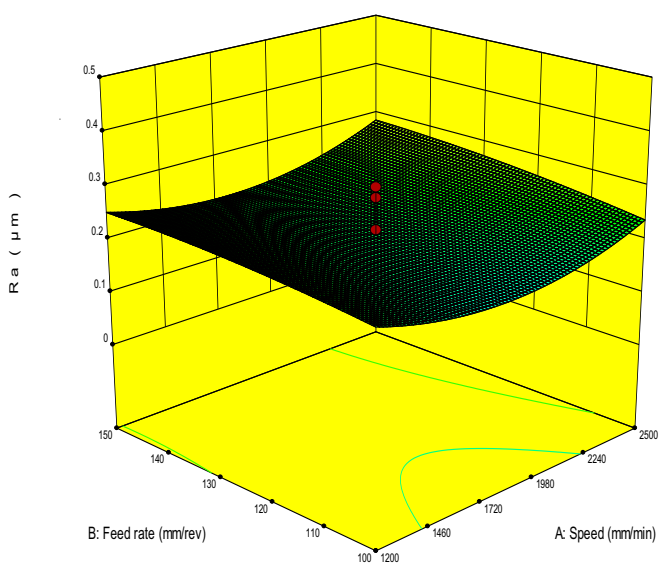

Figure 6. 3D surface plot Vs A, B. 


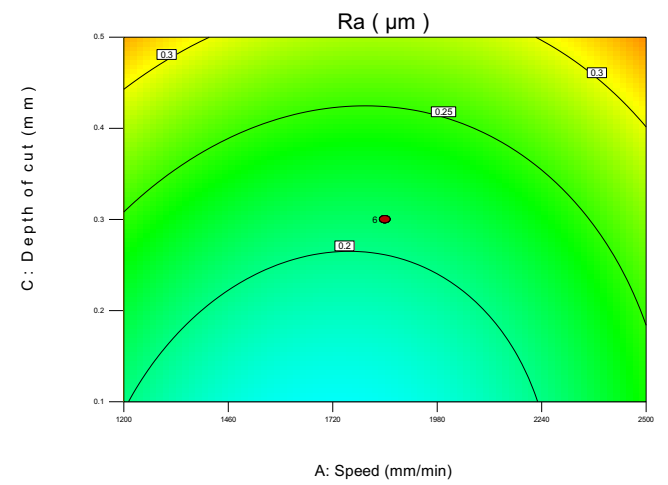

Figure 7. Ra contour plot Vs A, C.

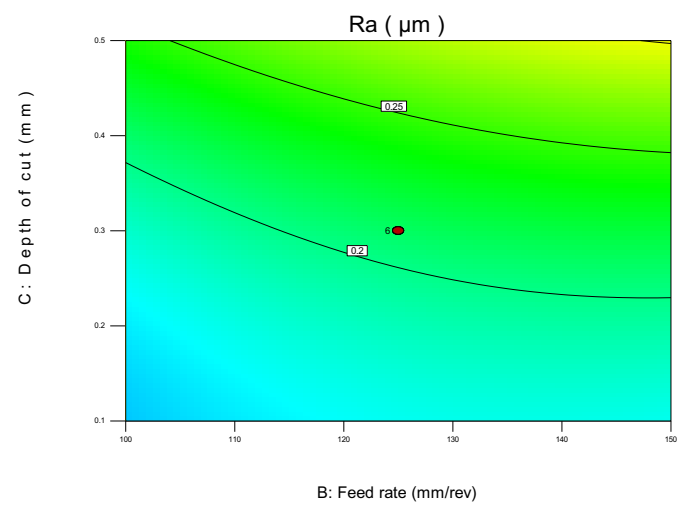

Figure 9. Ra contour plot Vs B, C.

Figure 1 shows the perturbation plot of cutting parameters. The plot indicates that with the increase of each parameter surface roughness increases. But most influential parameter is the depth of cut on surface roughness. Figure 2, 3 and 4 show the plot of the predictive model equation for different cutting parameters and its effect on surface roughness. Figure 2. Indicates that the surface roughness increases with an increase of speed and feed rate. Figure 3. Shows the influence of cutting speed and depth of cut on surface roughness. The trend of the graph clearly indicates that the surface roughness increases with the cutting speed and depth of cut. But surface roughness increase rapidly with increase in depth of cut compare to cutting speed. Figure 4 shows the effect of feed rate and depth of cut on surface roughness. It can be observed that the surface roughness increases with the feed rate and depth. More specifically, the depth of cut has more effect on surface roughness as compared to the feed rate. Figure 5 and 6 shows plot surface roughness Vs A, B at 0.3 depth of cut. Figure 7 and 8 shows plot surface roughness Vs A,C at 125 $\mathrm{mm} / \mathrm{min}$ feed rate. Surface roughness is low in intermediate cutting speed but is can be observed it increases with increase in depth of cut. Figure 9 and 10 shows plot surface roughness Vs B, C at $1850 \mathrm{rev} / \mathrm{min}$. The trend is simillar when feed rate and depth of cut increases surface roughness also increases.

The surface roughness is highly affected by cutting parameters. For surface roughness, it is observed that depth of cut is the most influential parameter followed by cutting speed and feed rate. The result shows surface roughness is comparable while machining in wet

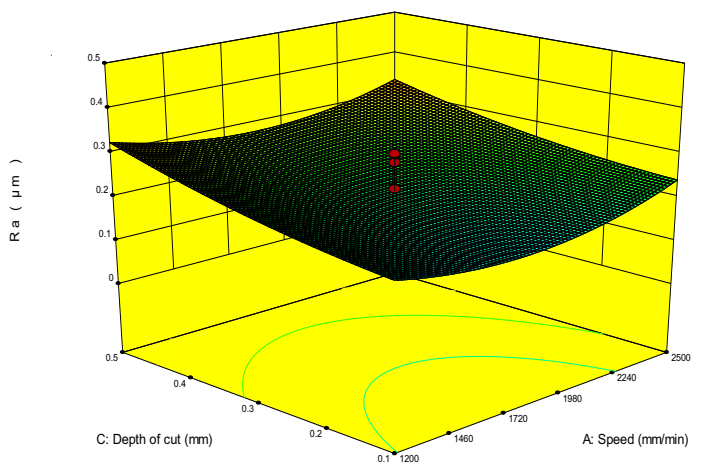

Figure 8. 3D surface plot Vs A, C.

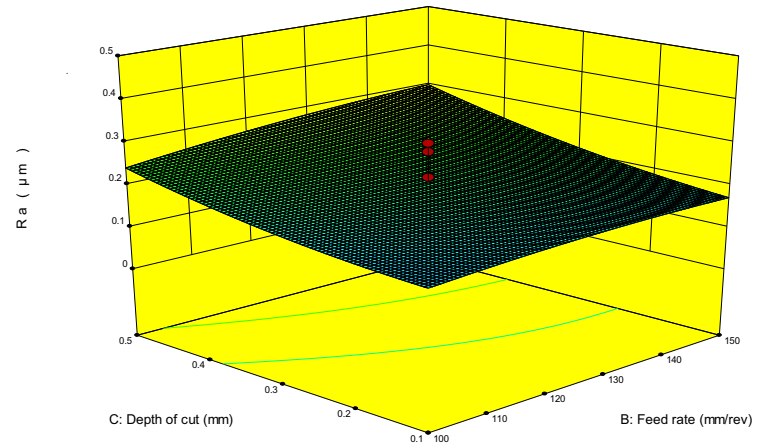

Figure 10. 3D surface plot Vs B, C.

condition and dry machining condition. The lowest surface roughness observed at cutting speed $1850 \mathrm{rev} / \mathrm{mm}$, depth of cut $0.3 \mu \mathrm{m}$ and feed rate $125 \mathrm{~mm} / \mathrm{min}$ under wet condition. Whereas lowest surface roughness at cutting speed $1850 \mathrm{rev} / \mathrm{mm}$, depth of cut $0.3 \mu \mathrm{m}$ and feed rate 85 $\mathrm{mm} / \mathrm{min}$ under dry condition.

\section{Conclusions}

In the present work, the effect of machining parameters (cutting speed, feed rate, depth of cut) on surface roughness was experimentally investigated. RSM used to develop the predictive mathematical model for machining of Inconel 718. The validity of the model is verified using ANOVA. The results show low surface roughness at lower cutting parameters in the selected range. The depth of cut has a higher influence on surface roughness compared to other two parameters (cutting speed and feed rate). Experiential results show, obtained surface roughness values are comparable in dry machining with coolant machining.

\section{References}

1. S. Pervaiz, A. Rashid, I. Deiab, M. Nicolescu, Influence of Tool Materials on Machinability of Titanium- and Nickel-Based Alloys: A Review, Materials and Manufacturing Processes 29, 219-252 (2014)

2. D. Ulutan, T. Ozel, Machining induced surface integrity in titanium and nickel alloys: A review, 
International Journal of Machine Tools and Manufacture 51, 250-280 (2011)

3. A. Jawaid, S. Koksal, S. Sharif, Cutting performance and wear characteristics of PVD coated and Carbide tools in face milling Inconel 718 aerospace alloy, journal of materials journal of materials processing technology 116, 2-9 (2001)

4. J. Zhou, V. Bushlya, R.L. Peng, Z. Chen, S. Johansson, J.E. Stahl, Analysis of Subsurface Microstructure and Residual Stresses in Machined Inconel 718 with PCBN and A12O3-SiCw Tools, Procedia CIRP 13, 150-155 (2014)

5. T. Kivak, Optimization of surface roughness and flank wear using the Taguchi method in milling of Hadfield steel with PVD and CVD coated inserts, Measurement 50, 19-28 (2014)

6. D. Philip Selvaraj, P. Chandramohan, M. Mohanraj, Optimization of surface roughness, cutting force and tool wear of nitrogen alloyed duplex stainless steel in a dry turning process using Taguchi method, Measurement 49, 205-215 (2014)

7. M. Sarıkaya, A. Güllü, Taguchi design and response surface methodology based analysis of machining parameters in CNC turning under MQL, Journal of Cleaner Production 65, 604-616 (2014)

8. P.J. Arrazola, A. Kortabarria, A. Madariaga, J.A. Esnaola, E. Fernandez, C. Cappellini, D. Ulutan, T. Özel, On the machining induced residual stresses in IN718 nickel-based alloy: Experiments and predictions with finite element simulation, SIMPAT 41, 87-103 (2014)

9. M.S. Kasim, C.H . Che Haron, J.A. Ghani, M.A. Sulaiman, Prediction Surface Roughness in HighSpeed Milling of Inconel 718 under Mql Using Rsm Method, Middle-East Journal of Scientific Research 13, 264-272 (2013)

10. Y. Sahin, A.R. Motorcu, Surface roughness model for machining mild steel with coated carbide tool, Materials \& Design 26, 321-326 (2005)

11. R. Kumar, S. Chauhan, Study on surface roughness measurement for turning of $\mathrm{Al} 7075 / 10 / \mathrm{SiCp}$ and $\mathrm{Al}$ 7075 hybrid composites by using response surface methodology (RSM) and artificial neural networking (ANN), Measurement 65, 166-180 (2015)

12. M. Alauddin, M.A. Mazid, A.E.B. b, M.S.J. Hashmi, Cutting forces in the end milling of Inconel 718, Journal of Materials Processing Technology 77, 153159 (1998)

13. R.M. Arunachalam, M.A. Mannan, A.C. Spowage, Surface integrity when machining age hardened Inconel 718 with coated carbide cutting tools,
International Journal of Machine Tools and Manufacture 44, 1481-1491 (2004)

14. M. Nalbant, A. Altın, H. Gökkaya, The effect of cutting speed and cutting tool geometry on machinability properties of nickel-base Inconel 718 super alloys, Materials \& Design 28, 1334-1338 (2007)

15. S. Amini, M.H. Fatemi, R. Atef, High Speed Turning of Inconel 718 Using Ceramic and Carbide Cutting Tools, Arab J Sci Eng 39, 2323-2330 (2014)

16. Y.S. Liao, H.M. Lin, J.H. Wang, Behaviors of end milling Inconel 718 superalloy by cemented carbide tools, Journal of Materials Processing Technology 201, 460-465 (2008)

17. A. Devillez, G. Le Coz, S. Dominiak, D. Dudzinski, Dry machining of Inconel 718, workpiece surface integrity, Journal of Materials Processing Technology 211, 1590-1598 (2011)

18. Z. Hao, D. Gao, Y. Fan, R. Han, New observations on tool wear mechanism in dry machining Inconel718, International Journal of Machine Tools and Manufacture 51, 973-979 (2011)

19. R.B. da Silva, Á.R. Machado, E.O. Ezugwu, J. Bonney, W.F. Sales, Tool life and wear mechanisms in high speed machining of Ti-6Al-4V alloy with PCD tools under various coolant pressures, Journal of Materials Processing Technology 213, 1459-1464 (2013)

20. M. Imran, P.T. Mativenga, A. Gholinia, P.J. Withers, Comparison of tool wear mechanisms and surface integrity for dry and wet micro-drilling of nickelbase superalloys, International Journal of Machine Tools and Manufacture 76, 49-60 (2014)

21. M.Z.A. Yazid, C.H. CheHaron, J.A. Ghani, G.A Ibrahim, A.Y.M. Said, Surface integrity of Inconel 718 when finish turning with PVD coated carbide tool under MQL, Procedia Engineering 19, 396-401 (2011)

22. Y. Kamata, T. Obikawa, High speed MQL finishturning of Inconel 718 with different coated tools, Journal of Materials Processing Technology 192-193, 281-286 (2007)

23. S. Zhang, J.F. Li, Y.W. Wang, Tool life and cutting forces in end milling Inconel 718 under dry and minimum quantity cooling lubrication cutting conditions, Journal of Cleaner Production 32, 81-87 (2012)

24. F. Pusavec, H. Hamdi, J. Kopac, I.S. Jawahir, Surface integrity in cryogenic machining of nickel based alloy-Inconel 718, Journal of Materials Processing Technology 211, 773-783 (2011) 